\title{
TECHNOLOGY AND EQUIPMENT FOR PRESS MAGNETICALLY-IMPELLED ARC WELDING OF POSITION JOINTS OF SMALL-DIAMETER PIPES IN SITE AND STATIONARY CONDITIONS
}

\author{
V.S. KACHINSKY, S.I. KUCHUK-YATSENKO, M.P. KOVAL and E.I. GONCHARENKO \\ E.O. Paton Electric Welding Institute, NASU \\ 11 Kazimir Malevich Str., 03680, Kiev, Ukraine. E-mail: office@paton.kiev.ua
}

\begin{abstract}
Increase in the quality of welding of position butts of pipes in site conditions is a challenging task. The aim of the work was the development of technology and equipment for press magnetically-impelled arc welding (PMAW) of position butts of pipes of 18-64 mm diameter with wall thickness of up to $5 \mathrm{~mm}$, which is used for pipes of air ducts of railway cars, pipelines in the repair and construction of greenhouse complexes and other purposes of industrial application. The adaptive system for automatic control of energy input at PMAW and the pipe welding technology on its basis under the conditions providing a stable quality of joints were developed. The technology of PMAW of pipes of 18-64 mm diameter in the field conditions was developed based on the method of automatic control of gap between the pipe being welded, providing a stable energy input during welding. The new generation of equipment was designed, manufactured and passed the industrial tests for PMAW of pipes of 18-64 mm diameter in the field conditions using the systems of automatic control of main parameters of the process. 8 Ref., 3 Tables, 12 Figures.
\end{abstract}

Keywords : press welding with magnetically-impelled arc, induction of controlling magnetic field, pipelines

Welding of position circumferential welds of pipes of 18-64 mm diameter of carbon and low-alloyed steels is applied in different branches of industry, construction, power engineering and greenhouse economy. At the same time, different technologies of manual, automatic orbital gas-electric and gas welding are mainly applied. In the previous years, at the E.O. Paton Electric Welding Institute the technology of welding pipes of small diameter was developed applying press magnetically-impelled arc welding (PMAW). The technology and equipment were successfully implemented and used in the manufacture of different parts of tubular round section in the automobile industry [1]. The installations for PMAW of parts of tubular section are designed and manufactured.

PMAW [2-5] differs from the existing arc methods by high efficiency, quality stability of welded joints, high degree of mechanization and automation of the technological process. Welding is performed in the automatic mode, which significantly reduces the influence of welding operator on the quality of welded joints. In PMAW of steel pipes the welding consumables and shielding gas are not required.

This technology and equipment are used in welding of position pipe butts under stationary conditions. Here, the basic parameters of welding process are preset by the programs, the reproduction of which is possible at a strictly preset value of the arc gap between the ends of pipes being welded. In PMAW in the field conditions and repair works the fulfillment of this condition is not always possible. The experience of PMWA of different pipes, gained at the PWI, shows that to stabilize of the gap is possible by developing the systems of automatic control of its value during welding process.

The aim of the work was the development of technology and equipment for PMAW of position butts of pipes of 18-64 mm diameter with wall thickness of up to $5 \mathrm{~mm}$, which is applied for pipes of air ducts of railway cars, pipelines in the repair and construction of greenhouse complexes and other purposes of industrial use adapted to the conditions of site welding of position butts in the repair of pipelines. To solve the put problem, the following investigations were carried out:

- development of adaptive system of automatic control of the process of metal heating and formation of joints during PMAW of pipes of the specified sizes;

- investigations of deformational processes in PMAW in order to achieve the required reinforcement of the weld by determining the basic parameters of the machine drive;

- investigations of the influence of thermal cycles in welding pipes of specified sizes on the structure and mechanical properties of joints and development of welding technology; 


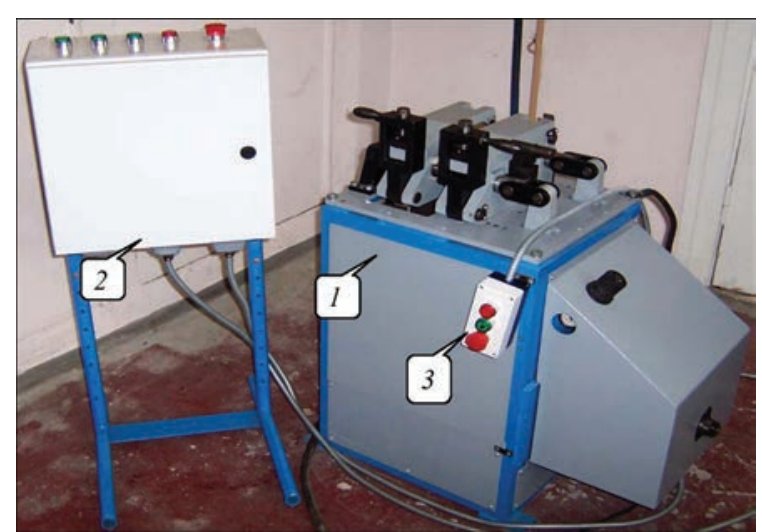

Figure 1. Installation MD101: 1 - welding machine; 2 - control cabinet; 3 - control panel

- development of mobile equipment for PMAW of small-diameter pipes.

To carry out investigations on welding the steel pipes of 32-51 mm diameter with wall thickness of $2.5-5.0 \mathrm{~mm}$ of steels 20 and 09G2S were used. The investigations were carried out in the laboratory machines MD101 and MD103 (Figures 1 and 2). Installation MD101 with a manual lever clamping and a pneumatic upsetting drive is designed for welding pipes of diameter from 12 to $51 \mathrm{~mm}$ with maximum cross-section area of $460 \mathrm{~mm}^{2}$ maximum outer diameter of $51 \mathrm{~mm}$ and wall thickness of $3 \mathrm{~mm}$. Power of the installation is not more than $40 \mathrm{kV} \cdot \mathrm{A}$. Weight of the installation is $250 \mathrm{~kg}$. Installation MD103 with a hydraulic drive of clamping and upsetting is designed for welding pipes of diameter from 40 to $120 \mathrm{~mm}$ with maximum cross-section area of $2000 \mathrm{~mm}^{2}$ and outer diameter of up to $120 \mathrm{~mm}$ with wall thickness of $5 \mathrm{~mm}$. Power of the installation is not more than $70 \mathrm{kV} \cdot \mathrm{A}$. Weight of the installation is $940 \mathrm{~kg}$. A significant weight of installations MD101 and MD103 does not allow applying them in welding in the site conditions.

The metallurgical examinations were performed in microscopes «Neophot-32» and «Versomet» at different magnifications. The value of microhardness was measured at $100 \mathrm{~g}$ load in the LECO microdurometer M-400. The grain size was determined according to the scales of GOST 5639-82. The chemical composition of steels is given in Table 1.

One of the main technological parameters influencing a stable movement of the arc in the magnetic field is the magnetic induction. As the investigations showed, at the low values of magnetic induction the arc burns unstable with short circuits. From the point

Table 1. Chemical composition of steels used, wt.\%

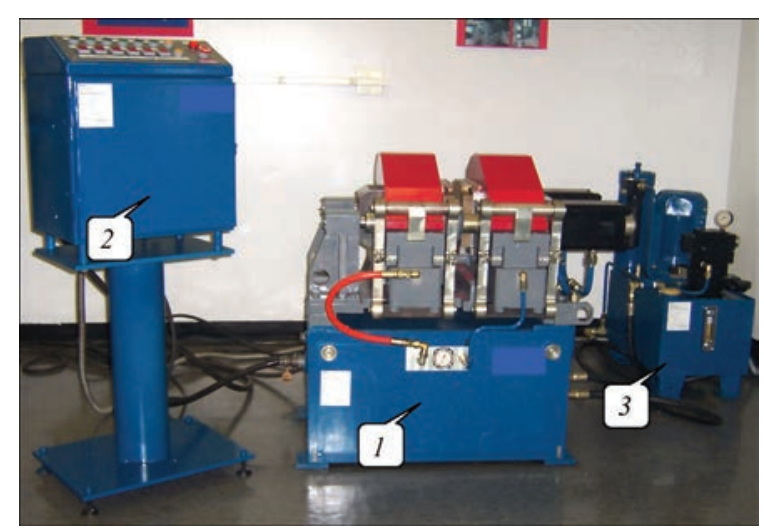

Figure 2. Installation MD103: 1 - welding machine; 2 - control cabinet; 3 - pump station

of view of power, for a stable arc movement it is desirable to provide the optimal induction in the gap. The optimal parameters of the field were accepted those, which could be realized later for using in the industrial conditions.

A stable arc movement depends also on the gap size, parallelism of ends and bevel angle of edges of pipes to be welded. The size of the arc gap, where the induction of controlling magnetic field is present and the arc is moved, largely determines the quality of welded joints. This parameter is determined from the requirement of stable arc excitation, its stable movement at the maximum possible time of burning, achieving the highest rotation speed. In the investigated range of pipes the value of the gap, as was established by the experiments, is in the range of $1.2-1.8 \mathrm{~mm}$. For the pipes with a small wall thickness (up to $2 \mathrm{~mm}$ ) this gap is $1.2-1.5 \mathrm{~mm}$, for the pipes with wall thickness of $5 \mathrm{~mm}$ it is in the range of $1.6-1.8 \mathrm{~mm}$.

On the basis of the carried out investigations the system for automatic control of the arc gap size during heating using high-speed magnetically-impelled arc was developed, which allows maintaining the optimum value during the whole heating period, regardless of the initial value of the gap. The system allows starting a stable arcing process even in the case of excitation with a short circuit, which greatly simplifies the alignment of pipe edges at the site assembly of butts and also reduces the requirements to the accuracy of cutting of pipe ends before welding. The system for automatic control of heating process of pipes in PMAW was patented in the leading countries and significantly widends the application of this technology in welding in the field conditions $[6,7]$.

The principle of arc gap regulation is based on the method of processing the feedback signal between the

\begin{tabular}{|c|c|c|c|c|c|c|c|c|c|c|}
\hline Grade of steel & $\mathrm{C}$ & $\mathrm{Si}$ & $\mathrm{Mn}$ & $\mathrm{P}$ & $\mathrm{S}$ & $\mathrm{Cu}$ & $\mathrm{Ni}$ & $\mathrm{Cr}$ & $\mathrm{Mo}$ & $\mathrm{Al}$ \\
\hline 20 & 0.20 & 0.24 & 0.47 & 0.015 & 0.016 & 0.05 & 0.05 & 0.25 & 0.05 & 0.01 \\
\hline 09G2S & 0.11 & 0.75 & 1.38 & 0.035 & 0.037 & 0.28 & 0.29 & 0.29 & 0.09 & $\mathrm{~N} / \mathrm{D}$ \\
\hline
\end{tabular}


voltage drop at the welding arc and the subsequent controlling the effect on the device for movement of movable part in the welding machine. The block-diagram of the regulator is shown in Figure 3.

The regulation of arc gap is performed as follows. Before the start of the welding process, the pipes to be welded with the as-abutted ends are clamped into the movable and stationary parts of the welding machine. Before the welding cycle starts the power source is switched on. The voltage on the movable and fixed bodies of the welding machine is equal to zero (short-circuit mode). At a zero signal of input voltage the opening of the movable part of the machine to the preset value of arc voltage occurs. The excitement of welding arc occurs and the process of heating the pipe ends begins. The signal corresponding to the voltage drop at the welding arc is transmitted to the input of a rating amplifier. In the process of pipe heating from the output of the rating amplifier the signal is transmitted to the input of the analog-digital converter and is converted into a sequence of package data corresponding to changes in voltage value at the welding arc moving in the gap between the pipe ends. In the software-hardware complex based on PC the data package is processed by the program of recording the voltage drop at the arc. Carrying out the continuous analysis of these data, the system influences the movable part of the welding installation, maintaining the arc voltage within the preset limits in order to provide a stable movement of the arc at the ends of pipes being welded. The use of the system allowed producing high-quality joints at a lower energy input and, respectively, heating and deformation of pipe ends, as far as heating stabilization allowed narrowing the excessive reserve of energy input envisaged for its reduction at the deviations of parameters.

Figure 4 shows the diagram of temperature distribution in welding of pipes of $42 \times 3 \mathrm{~mm}$ using the method of flash-butt welding (FBW) and PMAW, characterizing the temperature distribution in the metal of HAZ and along the line of structure joining.

The investigation of thermal cycles in the period of pipes heating using thermocouples and tests of joints showed that the decisive factor influencing the quality of joints is the temperature of heating pipe ends before their compression allowing producing the sufficient deformation during upsetting. The optimum temperature of heating of the area located at the distance of $1 \mathrm{~mm}$ from the pipe end is up to $1000-1100{ }^{\circ} \mathrm{C}$. The heating duration, in case the other parameters are maintained constant, remains in the narrow range. Its value depends on the arc current. The overheating of pipe ends by the moving arc leads to the appearance of molten bridges in the gap and re-

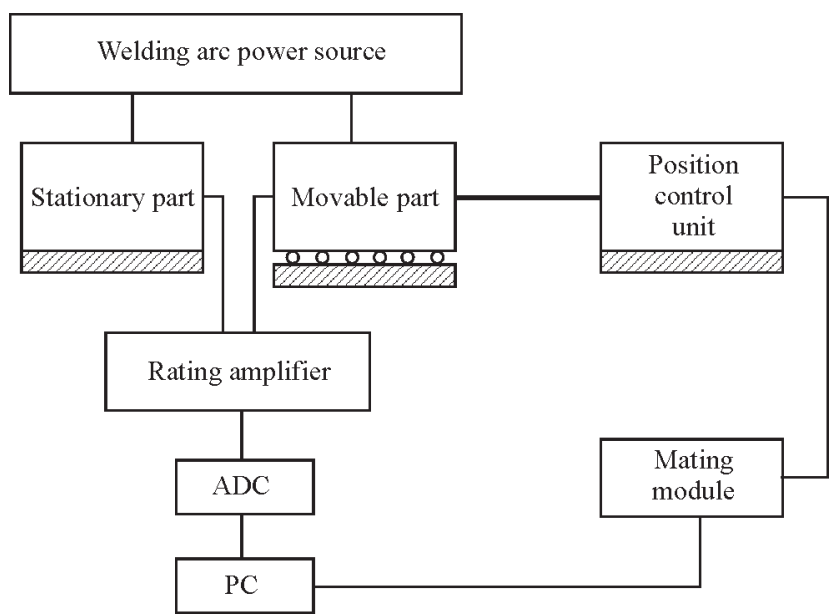

Figure 3. Block-diagram of arc gap regulator

duction in the speed of the stable arc movement. The arc under the influence of magnetic field moves in the gap between the ends of the pipes. A high speed of the $\operatorname{arc}$ (up to $140 \mathrm{~m} / \mathrm{s}$ ) on the pipes of small diameter allows obtaining a uniform heating across the pipe ends over the entire welded surface. For welding the machines were equipped with a drive, which allows changing the value of the arc gap between the pipe ends as well as regulating the amount of deformation during upsetting.

Development of welding technology. Figure 5 presents different types of welded joints of pipes of $38 \times 3 \mathrm{~mm}$ produced in the field conditions. The application of the system stabilized the gap value and energy input during the whole heating period, that allowed obtaining a stable temperature distribution during heating the pipes with wall thickness from 3 to $5 \mathrm{~mm}$ (see Figure 4).

In press welding of pipes the weld reinforcement is formed on the inner and outer pipe surface. Depending on the service conditions of welded joints and pipe structures the reinforcement is removed by machining or retained in the structure. During welding

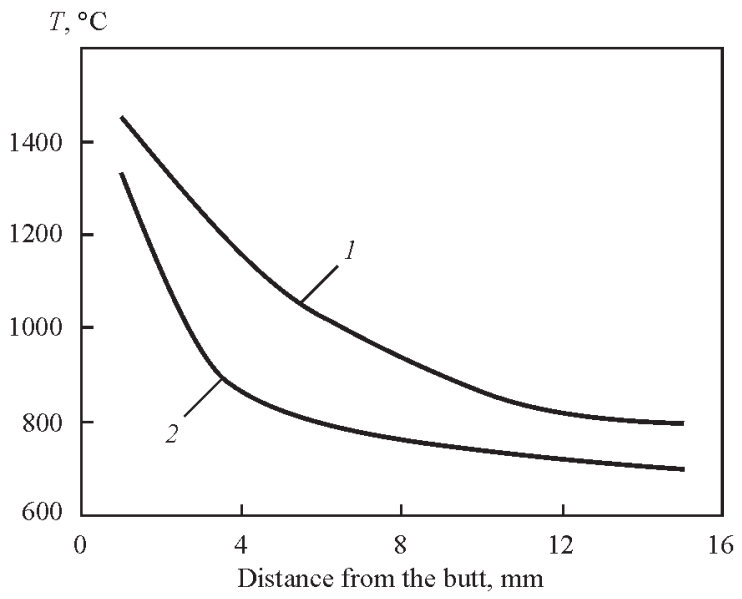

Figure 4. Determination of temperature in welding of pipes of $42 \mathrm{~mm}$ diameter with wall thickness of $3 \mathrm{~mm}: 1-\mathrm{FBW} ; 2$ PMAW 

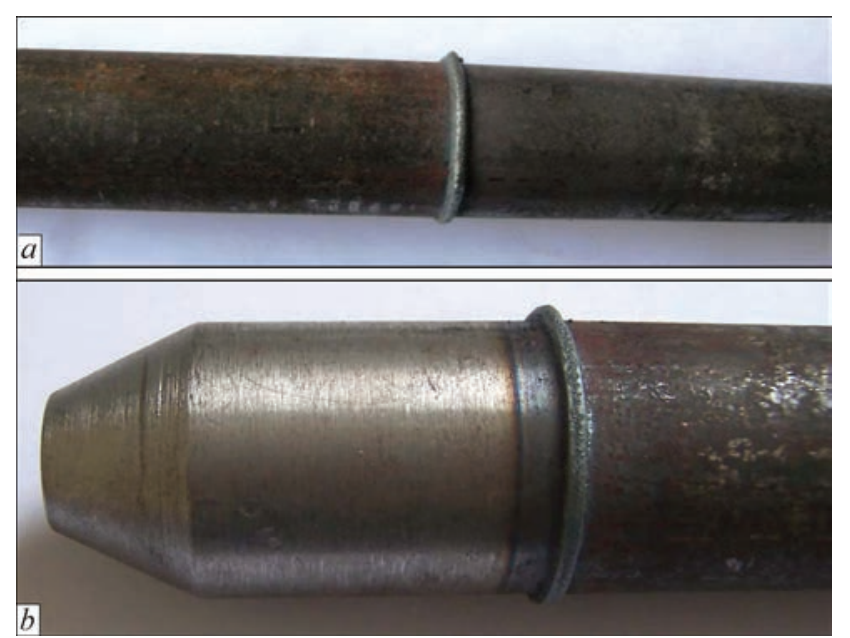

Figure 5. Welded joints of pipes of $38 \times 3 \mathrm{~mm}: a$ - pipe with pipe; $b$ - pipe to plug

of position butts of pipes the outer flash, if necessary, is removed and the inner one is admitted on the condition that it does not exceed the preset value. This requirement creates additional tasks in the development and searching of optimal thermal deformation cycles in welding. By controlling the energy input to the heated pipe ends and the allowance for upsetting, it was succeeded to reduce the amount of inner weld reinforcement (Figure 6).

In welding the course of the process is influenced by different factors, which causes the need in testing the quality of welded joints. The main condition for the welded joint formation is a process of a combined plastic deformation of the parts. The process of forming joints is influenced by the following factors:

- state of the pipe ends (surface temperature, presence of microroughness, oxide films and other contaminants);

- temperature distribution in the pipe ends being welded;

- value and character of ends deformation during upsetting.

From the results of the carried out investigations the technology of PMAW of pipes of small diameter of up to $64 \mathrm{~mm}$ was developed. The basic parameters of welding are given in Table 2.

Figure 7 shows the microstructure along the line of joining the pipes of $42 \times 4 \mathrm{~mm}$ welded using the method of PMAW. The band of joining is quite clearly ex-

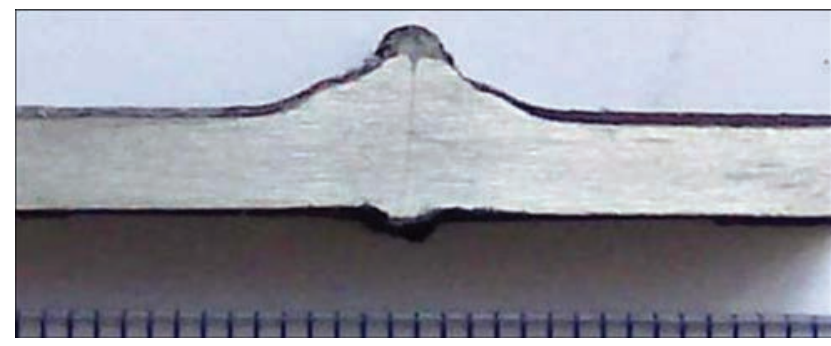

Figure 6. Macrosection of welded joint of pipe of $42 \times 3.5 \mathrm{~mm}$
Table 2. Basic technological parameters of welding pipes

\begin{tabular}{|c|c|c|c|c|}
\hline $\begin{array}{c}\text { Grade } \\
\text { of steel }\end{array}$ & $\begin{array}{c}\text { Size, } \\
\mathrm{mm}\end{array}$ & $\begin{array}{c}\text { Time } \\
\text { of welding, } \\
\mathrm{s}\end{array}$ & $\begin{array}{c}\text { Upsetting } \\
\text { force, } \mathrm{kN}\end{array}$ & $\begin{array}{c}\text { Shortening } \\
\text { of pipes, } \\
\mathrm{mm}\end{array}$ \\
\hline 20 & $38 \times 3$ & 9 & 24 & 3.8 \\
\hline 20 & $42 \times 5$ & 14 & 40 & 4.7 \\
\hline $09 \Gamma 2 \mathrm{C}$ & $42 \times 4$ & 12 & 37 & 3.7 \\
\hline 09Г2C & $48 \times 3.5$ & 13 & 35 & 3.4 \\
\hline
\end{tabular}

pressed throughout the whole height of the weld, its width is $40-60 \mu \mathrm{m}$.

The microstructure of HAZ metal in the area of coarse grains is ferrite-pearlite. Pearlite is precipitated in the form of separate grains in the composition of ferrite-pearlite mixture. The number of the grain in the coarse-grain c area orresponds to 6-5. The hardness amounts to HV1-1930-2210 MPa. At the area of normalization (Figure 8) the structure is fine-grained (number is 9-10 according to GOST 5639-82), and ferrite-pearlite with the predominance of a ferrite component, the width of the area is $1400 \mu \mathrm{m}$, the hardness is HV1-1640-1870 MPa. The base metal (Figure 9) represents a ferrite-pearlite mixture with obvious traces of rolling, the number of grains is 8 according to GOST 5639-82. The hardness of the base metal is HV1-1510-1710 MPa. The width of HAZ of welded joint is $6800 \mu \mathrm{m}$.

The hardness was measured along the BM-HAZjoining line-BM-HAZ line at $100 \mathrm{~g}$ load and 500, 300, 200 and $100 \mu \mathrm{m}$ step. The value of hardness is shown in Figure 10. The $H V 1$ hardness of joining band is $2150,1990,2280,2060,2280$ and $2060 \mathrm{MPa}$. The thermal cycle at PMAW is characterized by a rapid heating and cooling. In general, the metal structure is characterized by finer grain and smaller width of HAZ than in other types of pressure welding of similar products. The cooling rate is much higher in PMAW than in FBW, that leads to increase in hardness along the line of welded joint in PMAW. The microstructure of joint band consists mostly of lamellar ferrite with a

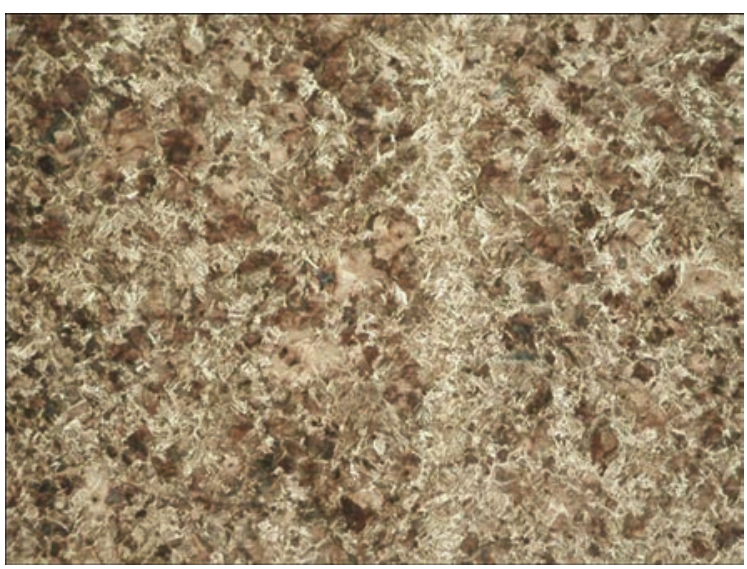

Figure 7. Microstructure $(\times 100)$ of steel 20 along the joining line of PMA-welded joint 


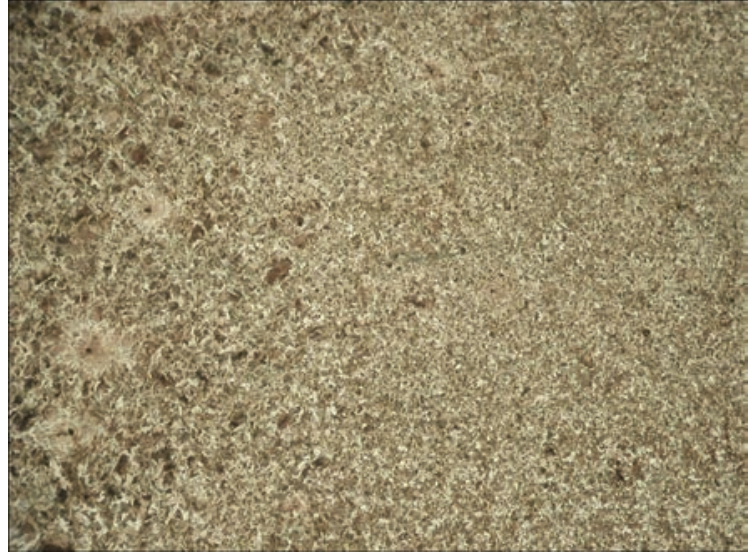

Figure 8. Microstructure $(\times 100)$ of area of complete recrystallization in PMA-welded joint

disordered second phase which has a higher hardness than free ferrite. It causes an increased hardness of the joining band as compared to FBW, where its structure represents mainly a polyhedral ferrite.

The mechanical properties of base metal and welded joints are given in Table 3. The analysis of the results of tests performed at 20 and $-20{ }^{\circ} \mathrm{C}$ temperature showed that mechanical properties of welded joints are at the level of those of base metal.

According to the results of investigations a mobile machine was designed for press welding of pipes of up to $51 \mathrm{~mm}$ diameter using magnetically-impelled arc [8]. For operation under the industrial and field conditions, mobile machine MD1 for press welding pipes of small diameter was manufactured.

\section{Main technical characteristics of MD1 installation}

Maximum cross-section area of pipes, $\mathrm{mm}^{2}$. . . . . . . . 450

Maximum diameter of pipes, $\mathrm{mm} \ldots \ldots \ldots \ldots \ldots \ldots$

Maximum upsetting force, $\mathrm{kN}(\mathrm{kgf}) \ldots \ldots \ldots \ldots . \ldots 30$ (3000)

Maximum clamping force, $\mathrm{kN}(\mathrm{kgf}) \ldots \ldots \ldots \ldots$. . . . 60 (6000)

Supply voltage, V . . . . . . . . . . . . . . . 380

Power consumption, $\mathrm{kV} \cdot \mathrm{A} \ldots \ldots \ldots \ldots \ldots \ldots \ldots \ldots \ldots$

Weight of machine, $\mathrm{kg} \ldots \ldots \ldots \ldots \ldots \ldots \ldots \ldots$

Dimensions of machine, $\mathrm{mm}$............. . 800×600×400

The process of PMAW in installation MD1, which consists of the machine, welding rectifier and control cabinet, is performed as follows.

The pipes to be welded are installed in the machine using clamping devices (Figure 11). The pipes are firmly clamped using drives of the machine. The arc is burning in the narrow gap between the pipe ends

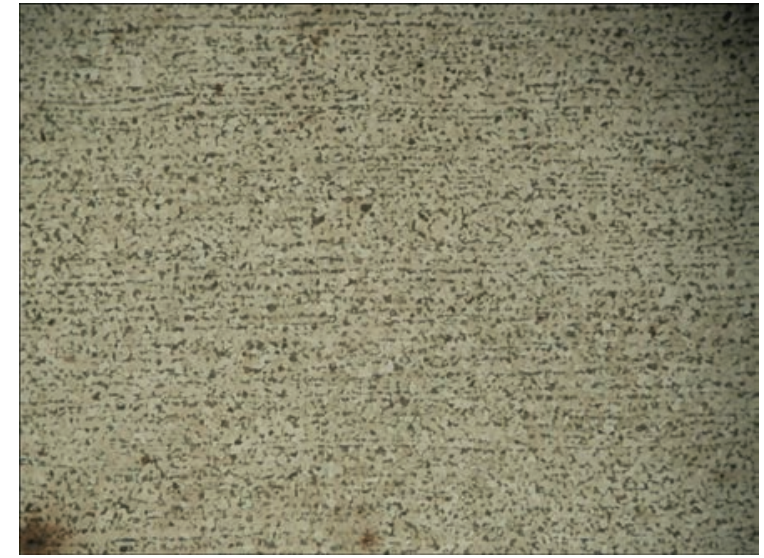

Figure 9. Microstructure $(\times 100)$ of base metal of PMA-welded joint

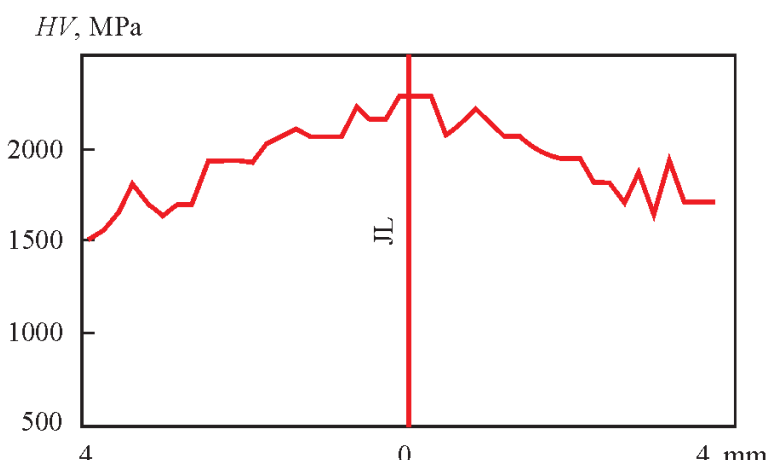

Figure 10. Hardness of PMA-welded joint along the BM-HAZJL-HAZ-BM line

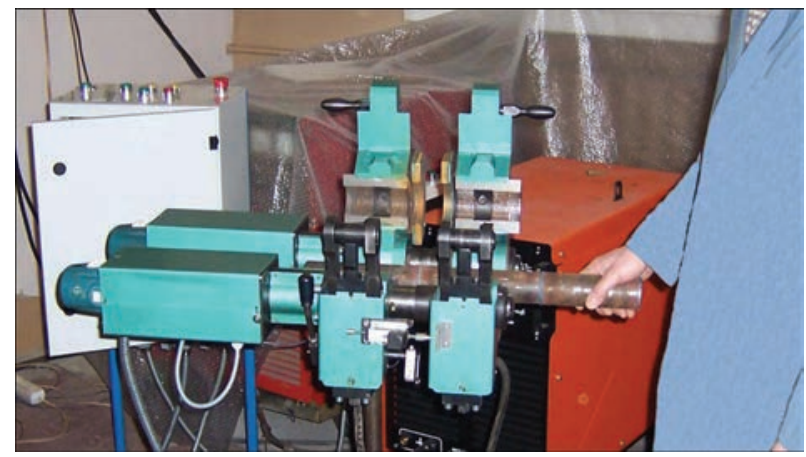

Figure 11. Installing of pipes into the clamping devices of designed welding machine MD1

(Figure 12). The welding is performed by heating the pipe ends until the state of plastic deformation. After heating the upsetting is performed.

Developed installation MD1 provides welding of pipes of $57 \mathrm{~mm}$ diameter both in the field as well as in the stationary conditions in the range of ambient

Table 3. Mechanical properties of PMA-welded joints of pipes

\begin{tabular}{|c|c|c|c|c|c|c|c|}
\hline \multirow{2}{*}{ Grade of steel } & \multirow{2}{*}{ Pipe size, mm } & \multicolumn{2}{|c|}{$\sigma_{t}, \mathrm{MPa}$} & \multicolumn{2}{|c|}{$K C V_{+20}, \mathrm{~J} / \mathrm{cm}^{2}$} & \multicolumn{2}{|c|}{$K C V_{-20}, \mathrm{~J} / \mathrm{cm}^{2}$} \\
\hline & & $\mathrm{BM}$ & $\mathrm{WJ}$ & $\mathrm{BM}$ & WJ & $\mathrm{BM}$ & $\mathrm{WJ}$ \\
\hline 20 & $38 \times 3$ & $\frac{508-525}{516.5}$ & $\frac{512-545}{528.5}$ & $\frac{56-58}{57}$ & $\frac{54-58}{56}$ & $\frac{56-59}{57.5}$ & $\frac{54-62}{58}$ \\
\hline 09G2S & $42 \times 5$ & $\frac{460-478}{469}$ & $\frac{453-484}{465}$ & $\frac{57.7-58.1}{57.9}$ & $\frac{59-78.1}{68.5}$ & $\frac{57.8-58}{57.9}$ & $\frac{64-74.5}{69.3}$ \\
\hline
\end{tabular}




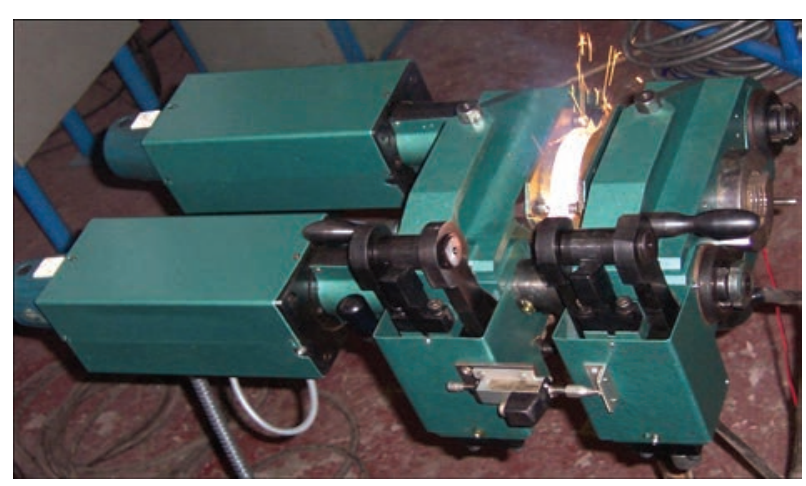

Figure 12. Process of press welding of $51 \times 4 \mathrm{~mm}$ pipes in MD1 machine

temperature from -40 to $40{ }^{\circ} \mathrm{C}$. The manufacture of welding mobile complexes based on this installation is possible.

\section{Conclusions}

The adaptive system for automatic control of energy input process at PWMA and the pipe welding technology on its basis were developed at the conditions providing a stable quality of joints.

The comprehensive investigations of pipe joints quality were carried out indicating the equal strength with the base metal according to all values, including the impact toughness.

The possibility of obtaining the limited sizes of flash due to optimization of thermal cycle was established.

The technology of PMAW of pipes of 18-64 mm diameter in the field conditions was developed, based on using the method of automatic control of gap size between the ends of pipes being welded providing a stable energy input, proposed by the authors.

The possibility of producing high-quality PMA-welded joints at minimum energy input and deformation during upsetting was shown in order to reduce the value of flash.

The comprehensive tests of welded joints of pipes of 18-64 mm diameter were carried out at a minimum energy input and indicate their practical equivalence with the base metal, including the values of impact toughness.

A new generation of equipment for PMAW of pipes of 18-64 $\mathrm{mm}$ diameter in the field conditions using the systems for automatic control of the basic process parameters was developed, manufactured and passed the industrial tests. The possibility of significant simplification of operations of alignment and assembly of pipes with the systems for automatic control was established.

The metallographic examinations showed absence of pores along the welded joint line. The measurement of hardness along the BM-HAZ-joining line-HAZBM line showed 10-15\% increase in the hardness, that is acceptable according to standard documents.

The technology for welding of pipes at the car repair enterprises of railway, construction and repair of greenhouse complexes was developed.

Mobile machine MD1 was designed for PMAW of small-diameter pipes under the stationary and field conditions.

1. Kuchuk-Yatsenko, S.I., Kachinsky, V.S., Ignatenko, V.Yu. et al. (2010) Magnetically-impelled arc butt welding of automobile parts. Austral. Welding J., 55(2nd Quart.), 40-48.

2. Ganovski, F.J. (1974) The magnetarc welding process. Welding Metal Fabr., 5, 206-213.

3. Edson, D.A. (1982) Magnetically impelled arc butt welding of thick wall tubes: IIW Doc. 726-82, July, 726.

4. Takagi, K., Arakida, F. (1982) Magnetically impelled arc butt welding of gas pipeline. Metal Constr., 10, 542-548.

5. Kuchuk-Yatsenko, S.I., Kachinsky, V.S., Ignatenko, V.Yu. et al. (2010) Magnetically-impelled arc butt welding of pipes of steel X70. Austral. Welding J., 55(2nd Quart.), 20-22.

6. Kuchuk-Yatsenko, S.I., Kachinskiy, V.S., Ignatenko, V.Yu. et al. Method of magnetically impelled arc butt welding. Pat. 6.211.489 BI US. Pat. 03.04.2001.

7. Kuchuk-Yatsenko, S.I., Kachinsky, V.S., Koval, M.P. Method of press welding. Pat. 100278 Ukraine. Reg. 10.12.2012.

8. Kuchuk-Yatsenko, S.I., Kachinsky, V.S., Galakhov, M.V. et al. Machine for pressure welding of pipes with heating by magnetically-impelled arc. Pat. 95360 Ukraine. Reg. 25.12.2014. 